\title{
Factors Influencing Continued Usage of Smartphone Games
}

\author{
Xiaoning Wang, Pan Zhang and Xing Fang \\ School of Economic and Management, Xi' an Shiyou University, \\ $X i$ 'an 710065, China \\ wangxn122s@126.com
}

\begin{abstract}
On the basis of the Expectation Confirmation Model in the context of IT, this paper studies factors which affect the continued usage behaviour of smartphone games. The results show that the satisfaction, the flow experience, the perceived system quality, the perceived peer influences, and the perceived usefulness have significant impacts on the continued usage behaviour of users of smartphone games, while the perceived cost and the conformation have no impact. The study results also uncover that the game developers may strengthen the users' continued usage behaviour via improving game quality, enhancing the flow experience of game, etc. However, the users of smartphone games are not sensitive to the usage cost, and the continued usage of smartphone games tends to cause game addiction against which precautions should be taken.
\end{abstract}

Keywords: Expectation Confirmation Model; Smartphone Games; Continued Usage behaviour; Game Addiction

\section{Introduction}

Mobile games have transformed from simple offline games, such as the Nokia Gluttonous Snake, to complicated 3D games and games which focus on the feeling of reality. In recent years, with the application of Bluetooth, Wi-Fi, and 3G network, due to its interconnectivity, portability, and conveniences (small screen), smartphone has become a prevailing tool for docking various game platforms. Based on statistics of Distimo, there are about $1 / 3$ of the applications are game applications in the Apple's AppStore as the representative of the mobile phone application store. Meanwhile, social network services, taking Facebook as an example, have also become important platforms for spreading social games. According to a study conducted by the U.S. Mobile Future (2013), the U.S. consumers daily spend 127 minutes on using mobile phone applications, among which game applications come first, accounting for $43 \%$. In $2013,43.1 \%$ of Chinese mobile phone netizens were mobile game users and the scale of game market of China Mobile amounted to RMB 14.85 billion Yuan, increased by $69.3 \%$ compared with that of 2012. It is an amazing growth rate. With the continuous improvement of the performance and the rapid spread of smartphones, smartphone games are certain to be a new growth engine in game industry [1]. However, the emergence of mobile games might make game addiction. The research on factors which lead to users' continued usage of mobile games has certain significance in researching their addiction to mobile games.

In the academic circle, there are a few papers regarding to the usage behaviour of mobile games. Sung and Yun [2] used the Technology Acceptance Model model to research the context of mobile multimedia services which focus on mobile games, with the purpose of checking the main function of the perceived enjoyment and related influence factors. The research results showed that the perceived enjoyment is impacted by the perceived usefulness, the perceived ease of use, and the direct behavioural intention, and that aesthetics and the flow experience are also key factors affecting the perceived enjoyment. Lin, Chen [3] used the TAM model to research related factors 
which affect the experience of smartphone game users. Considering that mobile games (emerging service) have not been extensively accepted by users, Zhou [4] established a user adoption model based on the flow theory, and the results showed that the ease of use, network connection quality, and the quality of game contents affected the flow experience. And the flow, social influence and cost to use determined users' usage intentions. Zhou considered that it was of vital importance to strengthen user experience in popularizing mobile games. Park and Baek [5] Studied the possible impacts of psychological factors on the user behaviour of mobile social network games (M-SNGs) and put forward the M-SNGs model. By using the model, they verified that not only the perceived enjoyment and perceived usefulness played a decisive role, but also the perceived mobility and sensory control and skills (motivators) could impact game players. All these studies were conducted only targeting the adoption, but there's barely any study on the continued usage behaviour of mobile games.

As a new medium for transmission, smartphone is widely used due to its everlasting network connection and abundant mobile applications and meanwhile smartphone has certain influence on users' usage behaviours. We select game applications which are frequently used in the application markets, researching main factors which impact smartphone users' continued playing of mobile games and issues that the mobile game providers should pay attention to when they design and popularize mobile games. In addition, based on the user behaviour theory, we analyze and summarize these main influence factors.

\section{Theoretical Backgrounds}

The information technology theory and information system adoption theory are originated from the field of management information system.

Based on the Expectation Confirmation Theory (ECT) of customer behaviour and the TAM model, Bhattacherjee [6] put forward a new Expectation Confirmation Model in the context of IT (ECM-IT) which is used to interpret the users' continuous use intentions of information technology, and test it under the background of network bank. Therefore, it is a groundbreaking theoretical contributions. Because the dependent variable in the ECM-IT model as shown in Figure 1 is the continuous use intention, Limayem, Hirt [7] extended the dependent variable to the continued usage behaviour based on this model and verify it by regarding Internet as the background. Soon, Bhattacherjee and Perols [8] got to know that the continuous use intention is uncertain so that users will change their use intentions to usage behaviours, so Bhattacherjee extended the dependent variable of the ECM-IT model to the continued usage behaviour.

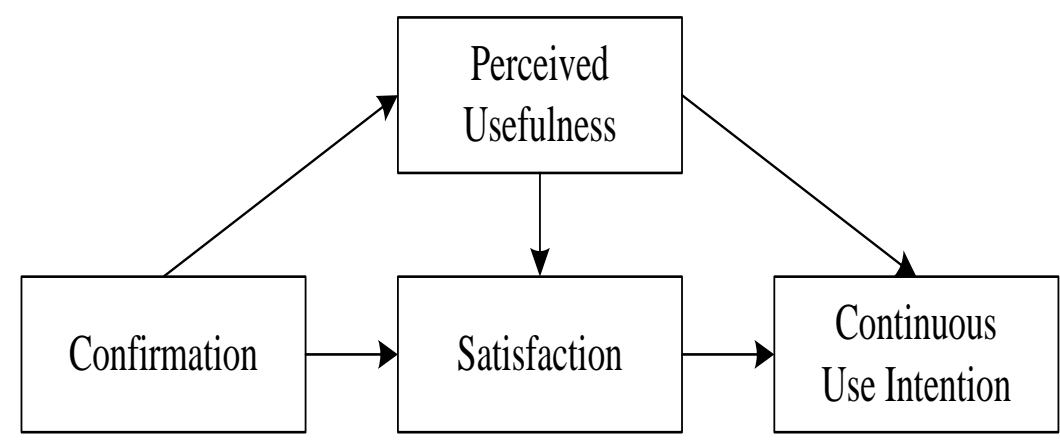

Figure 1. Expectation Confirmation Model in the Context of IT

At the initial stage of mobile products entering into the market, the researchers regard them as one part of the information system and then properly adjusted and introduced the 
typical theory models in the field of information system to conduct research on users' behaviours and intentions in adopting mobile phone. However, since smartphone (as a new medium) appeared in 2007, after observing people's life, we have found that most of people are conducting behaviours involving surfing the Internet, instant chat, and playing games with smartphone. Due to its interconnectivity, instantaneity, and usability, smartphone is easy to satisfy the needs of users and to motivate the users' use intentions partly. The initial adoption of smartphone refers to the selection of a majority of users. For the providers of smartphone game services, it is more important to keep the user's vitality and make continuous profits. The study of application of mobile phone based on ECM-IT model include: Hong and Thong [9]studied users' continued information technology usage behaviour on mobile internet via a comparison of three models; $\mathrm{Wu}$ and Chen [10] researched the mobile phone shopping, described users' perceived value dimension and extended the EMC-IT model; Wang and Oh [11] conducted an empirical study of experiences of users of Chinese mobile newspapers by using the ECM-IT model, with the results showing that the expectation, the satisfaction, and the perceived cost, for the users, have impacts on the continued usage of mobile newspapers. Liang and Yeh [12]studied the effect of use contexts(place where mobile games are used, work context, or recreation context) on the continuous use of mobile services by using the Theory of Reasoned Action model and TAM model, and the results shown that use contexts have main effects on users' continued use intentions. Kim [13] considered that mobile data services and applications focus on spreading and understanding user behaviours. On the basis of information system acceptance, Kim established his model, and the result indicated that the users' habits are more likely to affect their usage behaviours compared with consciousness. He also found that the user satisfaction, the perceived cost, and the usage behaviour contributed to the formation of the habits. According to characteristics of study directions, the authors use most of these models to form a new model via adding or reducing variables, which can support his theory.

This paper, based on the ECM-IT model, adds variables including the perceived cost (PC), the flow experience (FE), the perceived system quality (PSQ), and the perceived peer influences (PPI), establishes a smartphone game user continued usage model. On the basis of empirical study, the tendency of addiction to mobile games is interpreted. The model in discussion is of significance in measuring the impact of different variables on the continued usage behaviours of smartphone games.

\section{Hypotheses and Model}

\subsection{Continued Usage Behaviour}

This paper studies the continued usage of smartphone as well as addiction produced by it. Since the phenomenon of addiction can only be predicted by analyzing specific behaviour of smartphone users, we directly study the effects of continued usage behaviour. Based on relations between variables such as the perceived usefulness, the confirmation, the satisfaction, etc., which are proposed for ECM-IT model, we put forward the following hypotheses:

H1: The confirmation has a positive effect on the satisfaction

$\mathrm{H} 2$ : The satisfaction has a positive effect on the continued usage behaviour.

H3: The confirmation has a positive effect on the perceived usefulness.

H4: The perceived usefulness has a positive effect on the satisfaction.

H5: The perceived usefulness has a positive effect on the continued usage behaviour. 


\subsection{Perceived Cost}

From the perspective of mobile game providers, Park and Kim [5] pointed out that three most important factors for a successful mobile game are target, perception, and consumers' intention to pay, respectively. From the perspective of user, Deng and Lu [14] pointed out that when consumers adopt a mobile business service, the usage cost is one of the important factors affecting consumers' adoption and the usage of the service. The usage cost in discussion includes mobile data traffic fee, monthly package fee, and downloading fee. Different cost of the smartphone game may have different effects on usage and perception of different groups of consumers. This paper believes that the cost perceived by users may have an effect on the continued usage behaviour and puts forward the following hypotheses:

H6: The perceived cost has a negative effect on continued usage behaviour.

\subsection{Perceived Flow Experience}

Flow Experience theory was proposed by the psychologist Csikszentmihaly in 1975. It is described as a spontaneous activity which produces a pleasurable experience affected by the balance between skill and challenge. The experience may produce a perception which goes beyond the previous handling capacity of users, without limits. It always aspires for satisfaction and sense of accomplishment. Based on empirical studies conducted by Hsu and $\mathrm{Lu}$ [15] on flow experience of the application of the Internet, and the flow experience and medium addiction as theoretical category of technology addiction[16, 17], we propound the following hypotheses on addiction to smartphone games:

H7: The flow experience has a positive effect on the continued usage behaviour.

H8: The flow experience has a positive effect on the satisfaction.

\subsection{Perceived System Quality}

The DeLone and McLean [18](D\&M) system evaluation model indicates the perceived system quality is one of the six major factors for a successful information system. The system quality mentioned in the paper is related to stability, the response speed, frequency of malfunction, reliability, and other factors which are associated with smartphone game systems. The D\&M system evaluation model holds that perceived system quality has an effect on usage of the system and satisfaction [19, 20]. The D\&M system evaluation model also holds that system quality is one of the key factors affecting usage of a smartphone game system. Hence here are:

H9: The perceived system quality has a positive effect on the satisfaction.

H10: The perceived system quality has a positive effect on the continued usage behaviour.

H11: The perceived system quality has a positive effect on the flow experience.

H12: The perceived system quality has a positive effect on the perceived peer influences.

\subsection{Perceived Peer Influences}

Perceived peer influences means that a smartphone game is so interesting that users recommend the game to their peers. According to the Consumer Socialization Theory, the family influences, the mass media, and the peers influences are three factors (which may affect consumers' consumption decision) leading to consumer socialization. It is testified by social games that if a user discovers an interesting smartphone game, he or she is likely 
to recommend it to his or her peers [21]. Therefore, we put forward the following hypotheses:

H13: The perceived peer influences have a positive effect on the continued usage behaviour.

H14: The perceived peer influences have a positive on effect the satisfaction.

To sum up, we illustrate our research model in Figure 2:

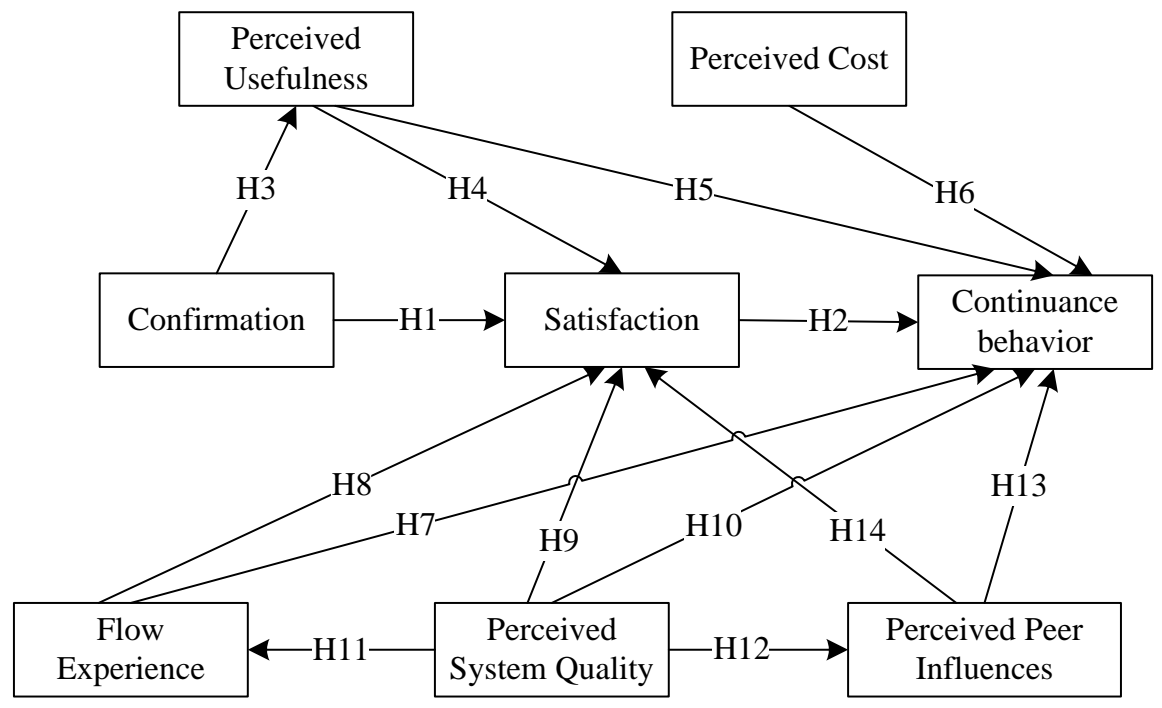

Figure 2. The Research Model

\section{Methodology}

\subsection{Measurement}

When we measure the variables in discussion, we adopts approaches used widely in relatedliterature as references. Meanwhile, considering properties of smartphone games as well as Chinese terminology, this paper slightly altered the measurement. It used the five-point Likert scale for the questionnaire, and invited two e-business experts to review the questionnaire. The questionnaire was distributed to 50 college students for pre-investigation after the experts revised it. At the same time, based on the feedback of pre-investigation, we adjusted some items on the questionnaire. Finally, we established 8 variables for 26 questions. Among the variables, the flow experience is made of 4 measures; the perceived cost is made of 3 measures; the perceived system quality is made of 4 measures; the perceived peer influences are made of 3 measures; the conformation is made of 3 measures; the perceived usefulness is made of 3 measures; the satisfaction is made of 4 measures; and the continued usage behaviour is made of 2 measures. Table 2 gives the detail information of these measures.

\subsection{Data Collection}

Through the questionnaire, we collect related data to test our model. People investigated are smartphone users, with 485 valid questionnaires returned. $57.7 \%$ of the valid papers were returned by males; and $42.3 \%$ by females. The 18-24-year-old and the 25-30-year-old persons account for $68.9 \%$ and $22.9 \%$ of the 485 people who returned valid questionnaires, respectively. Those who have a bachelor degree account for $76.7 \%$ of the 485 people. Among the people investigated, $58.6 \%$ are students. $73.8 \%$ of the students play smartphone games when they attend schools, work, or have a break. 52.2\% 
of the students play smartphone games when they go on a journey. The valid samples we collected for the study meet statistical requirements. Table 1 shows the information on the statistical samples.

Table 1. Respondents' Information (N = 485)

\begin{tabular}{llll}
\hline Measure & Option & N & $\%$ \\
\hline \multirow{2}{*}{ Gender } & Male & 280 & 57.7 \\
& Female & 205 & 42.3 \\
\hline \multirow{4}{*}{ Age } & $<18$ & 8 & 1.6 \\
& $18-24$ & 334 & 68.9 \\
& $25-30$ & 111 & 22.9 \\
Education & $31-35$ & 18 & 3.7 \\
& $>35$ & 14 & 2.9 \\
\hline \multirow{2}{*}{ Employment } & High school or below & 63 & 13 \\
& Bachelor's degree & 372 & 76.7 \\
& Master's degree or above & 50 & 10.3 \\
\hline \multirow{3}{*}{ When to play smartphone game } & Btudents & 284 & 58.6 \\
& Others & 201 & 41.4 \\
\cline { 2 - 4 } & On the way & 129 & 26.6 \\
& Vocation & 358 & 73.8 \\
& & 253 & 52.2 \\
& & 141 & 29.1 \\
\hline
\end{tabular}

\subsection{Measurement Model}

This paper adopts the Confirmative Factor Analysis (CFA) to check the reliability and validity of the measurement, and then uses the structural equation model software (Amos 20.0) to verify the hypotheses of the model. The validity of the model is validated via three forms including the aggregate validity, the convergent validity, and the discriminate validity.

Firstly, we use the AMOS to build an unconstrained CFA to analyze the aggregate validity of 8 variables ( 3 exogenous variables and 5 endogenous variables). The aggregate validity is realized by the investigation on Standardized factor loadings (SRC). The loads of each item should exceed 0.6 on their assumed structure and all loads should be significant $(\mathrm{p}<0.05, \mathrm{t}>=2.0)[22,23]$. The model has a good aggregate validity when the factor load is higher than 0.6.

Secondly, in order to determine the reliability, we need to evaluate the composite reliability (CR) and the average variance extracted (AVE) of measurement items of all variables. For obtaining a good reliability, CR should be larger than 0.60. AVE should be higher than 0.5 [24-26] and Cronbach's alpha should be higher than 0.6 [27]. In the final model, the CR and the AVE exceed 0.761 and 0.608, respectively, and the minimum of Cronbach's alpha is 0.737 , which indicates that the model has a good reliability and convergent validity. As shown in Table 2 . 
Table 2. Standardized Item Loadings, AVE, CR and Cronbach's Alpha

\begin{tabular}{|c|c|c|c|c|c|}
\hline Item & Wording & $\begin{array}{l}\text { Standardized } \\
\text { factor loadings }\end{array}$ & AVE & $\mathrm{CR}$ & $\begin{array}{l}\text { Cronbach } \\
\text { 's Alpha }\end{array}$ \\
\hline \multicolumn{6}{|c|}{ Flow Experience [15]. } \\
\hline FE1 & When playing Smartphone game, I focus on it. & 0.805 & \multirow{4}{*}{0.635} & \multirow{4}{*}{0.874} & \multirow{4}{*}{0.872} \\
\hline FE2 & When playing Smartphone game, I feel time flies. & 0.749 & & & \\
\hline FE3 & \multirow{2}{*}{$\begin{array}{l}\text { When playing Smartphone game, I threw myself into it. } \\
\text { When playing Smartphone game, I concentrate fully on the } \\
\text { game task. }\end{array}$} & 0.869 & & & \\
\hline FE4 & & 0.759 & & & \\
\hline \multicolumn{6}{|c|}{ Perceived Cost $[28,29]}$. \\
\hline PC1 & $\begin{array}{l}\text { I think it's too high to pay for the Internet when playing } \\
\text { Smartphone game. }\end{array}$ & 0.740 & \multirow{3}{*}{0.693} & \multirow{3}{*}{0.870} & \multirow{3}{*}{0.867} \\
\hline $\mathrm{PC} 2$ & $\begin{array}{l}\text { I think it's too expensive to download the Smartphone } \\
\text { game. }\end{array}$ & 0.921 & & & \\
\hline PC3 & $\begin{array}{l}\text { I think the monthly payments for play Smartphone game is } \\
\text { too high. }\end{array}$ & 0.826 & & & \\
\hline \multicolumn{6}{|c|}{ Perceived System Quality $[18,20]}$. \\
\hline PSQ1 & Smartphone game system has high stability. & 0.794 & \multirow{4}{*}{0.625} & \multirow{4}{*}{0.869} & \multirow{4}{*}{0.868} \\
\hline PSQ2 & Smartphone game system response quickly. & 0.708 & & & \\
\hline PSQ3 & Smartphone game system seldom break down. & 0.820 & & & \\
\hline PSQ4 & Smartphone game system has high reliability. & 0.834 & & & \\
\hline \multicolumn{6}{|c|}{ Perceived Peer Influences $[15,30]}$. \\
\hline PPI1 & $\begin{array}{l}\text { I play Smartphone games, for my class or friends are } \\
\text { playing. }\end{array}$ & 0.793 & \multirow{3}{*}{0.653} & \multirow{3}{*}{0.850} & \multirow{3}{*}{0.847} \\
\hline PPI2 & $\begin{array}{l}\text { The most important is, my class or friends wish I would } \\
\text { play the Smartphone game. }\end{array}$ & 0.851 & & & \\
\hline PPI3 & My class or friends suggest this Smartphone game to me. & 0.779 & & & \\
\hline \multicolumn{6}{|c|}{ Conformation [6]. } \\
\hline C1 & Smartphone game is interesting more than I expected. & 0.759 & \multirow{3}{*}{0.679} & \multirow{3}{*}{0.863} & \multirow{3}{*}{0.866} \\
\hline $\mathrm{C} 2$ & $\begin{array}{l}\text { The experience of play Smartphone game is better than I } \\
\text { expected. }\end{array}$ & 0.926 & & & \\
\hline $\mathrm{C} 3$ & $\begin{array}{l}\text { The sense of achievements in play Smartphone game is } \\
\text { better than I expected. }\end{array}$ & 0.777 & & & \\
\hline \multicolumn{6}{|c|}{ Perceived Usefulness $[15,20,31]$} \\
\hline PU1 & Smartphone game can let me to achieve the game purpose & 0.781 & \multirow{3}{*}{0.608} & \multirow{3}{*}{0.823} & \multirow{3}{*}{0.821} \\
\hline PU2 & Smartphone game can satisfiy my game purpose & 0.839 & & & \\
\hline PU3 & Smartphone game far from my game purpose & 0.715 & & & \\
\hline \multicolumn{6}{|c|}{ Satisfaction[8]. } \\
\hline S1 & Very dissatisfied...Very satisfied & 0.834 & \multirow{4}{*}{0.781} & \multirow{4}{*}{0.935} & \multirow{4}{*}{0.935} \\
\hline $\mathrm{S} 2$ & very frustrated...get full satisfaction & 0.865 & & & \\
\hline S3 & Terrible...much pleasure & 0.927 & & & \\
\hline S4 & very unhappy...very happy & 0.907 & & & \\
\hline Contin & usage behavior [8]. & & & & \\
\hline CB1 & $\begin{array}{l}\text { The frequency of play Smartphone games per day: } \\
0 ; 1-2 ; 3-4 ; 5-6 ; \text { Above } 6 \text { times }\end{array}$ & 0.804 & & & \\
\hline CB2 & $\begin{array}{l}\text { The time of play Smartphone games per day: } \\
0 ; 0.1-1 \mathrm{~h} ; 2-3 \mathrm{~h} ; 4-6 \mathrm{~h} ; \text { Above } 6 \mathrm{~h}\end{array}$ & 0.763 & 0.614 & 0.761 & 0.737 \\
\hline
\end{tabular}

Lastly, in estimating the discriminate validity, we use the square root of the AVE values of all factors and the coefficients of correlation among the factors. Table 3 presents the calculation results, with the diagonal being the square root of AVE values, and off-diagonal being the coefficients of correlation among the factors. The coefficients of correlation are smaller than corresponding diagonal values, conforming to the value proposed by [32], which indicates that the variables have a good discriminate validity.

Table 3. The Square Root of AVE (Shown as Italics at Diagonal) and Factor Correlation Coefficients

\begin{tabular}{lllllllll}
\hline & PC & PPI & FE & PU & S & C & CB & PSQ \\
\hline PC & 0.832 & & & & & & & \\
PPI & 0.387 & 0.808 & & & & & & \\
FE & 0.369 & 0.481 & 0.797 & & & & & \\
PU & 0.035 & 0.001 & 0.012 & 0.78 & & & & \\
S & 0.266 & 0.546 & 0.492 & 0.011 & 0.884 & & & \\
C & -0.063 & -0.066 & -0.058 & -0.008 & -0.059 & 0.824 & & \\
CB & 0.268 & 0.454 & 0.441 & -0.083 & 0.51 & -0.032 & 0.784 & \\
PSQ & 0.24 & 0.519 & 0.492 & -0.023 & 0.548 & -0.019 & 0.488 & 0.791 \\
\hline
\end{tabular}




\subsection{Structural Model}

After the measurement model is guaranteed, this paper evaluates the structural model to prove the structural model has a good aggregate validity. Results show that the chi-square value of the structural model is 560.252 in the condition that the degree of freedom is 285 , the chi-square test value is 1.966 , the Goodness-of-Fit Index is 0.981 , the Adjusted Goodness-of-Fit Index is 0.899, the Normed Fit Index is 0.926, the Comparative Fit Index is 0.962, the RMR is 0.088, and the Root Mean Square Error Approximation is 0.045 , which are acceptable.

Results of analyses for the structural model are shown in Figure 3. Four hypotheses including $\mathrm{H} 1, \mathrm{H} 3, \mathrm{H} 5$, and $\mathrm{H} 6$ are refuted, and the other paths are significant. The results indicate that determinants of the continued usage behaviour in smartphone game are the perceived system quality $(\beta=0.345)$, the satisfaction $(\beta=0.324)$, the perceived peer influence $(\beta=0.201)$, the flow experience $(\beta=0.198)$ and the perceived usefulness $(\beta=0.006)$. The perceived confirmation and the perceived cost are not the decisive factors for usage behaviours.

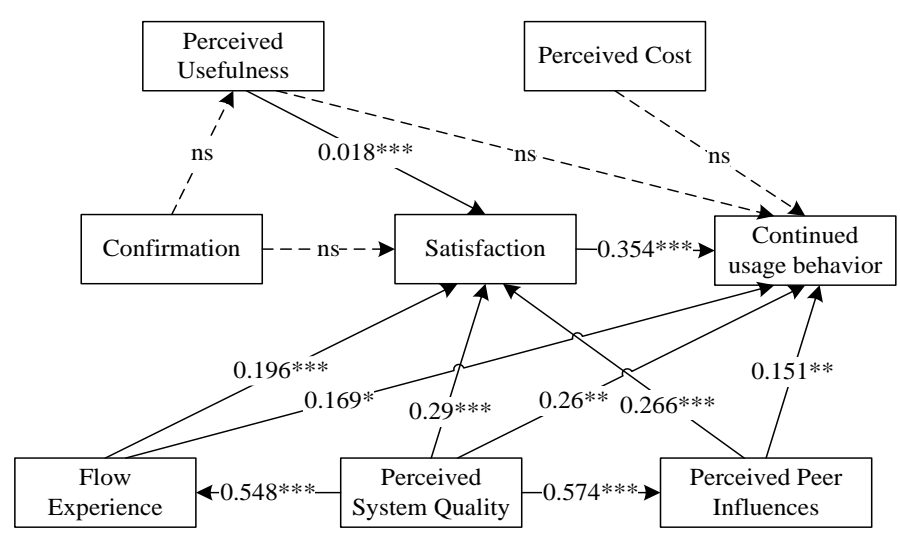

Notes: Significant at: ${ }^{*}<<0.05, * * p<0.01, * * * p<0.001$, ns - Not significant.

Figure 3. Results of Structural Equation Model

\section{Discussion}

Based on previous studies on mobile game playing as well as the ECM-IT model, we study continued usage of smartphone games, and discover the following:

The perceived usefulness has no effect on the continued usage behaviour, but it has a weak effect on satisfaction. The perceived usefulness means people may do things better when using a certain technology. Therefore, they are more inclined to use the technology. Smartphone game, because of its unique properties, is more likely to help us regulate our emotions, have fun, relax, or even kill time. From this perspective, we can tell that smartphone game should have a weak effect on satisfaction of consumers. However, it is generally acknowledged that smartphone game is no useful to our work or learning. For games providers, although continued usage of mobiles leads to addiction, they can take advantage of the addiction to develop the learning and puzzle game as a beneficial attempt.

The confirmation has no effect on satisfaction and perceived usefulness, which is consistent with most ECM model-based theories. Burke and Kovar [33] proposed that if users are not familiar with a mobile game or if they have ambiguous expectations to mobile gaming, the confirmation has no effect on consumer evaluation. It is a principle that mobile games should be designed to satisfy the challenge, curiosity, desire for control, or illusion of the users. These feelings seems to become so insipid when users are familiar with a smartphone game [34]. We believe that just because users are familiar 
with the smartphone game, the confirmation has no effect on the satisfaction. Meanwhile, Bartle [35] showed that pursuing fame and wealth in the virtual world, making friends with game players, and escaping from the real life are three major motivations for game playing. Since they have an unclear expectations before start a game play, this causes the confirmation has no effect on perceived usefulness.

The perceived cost has no effect on behaviour, which indirectly testifies that continued usage behaviour leads to addiction. When the continued usage behaviour become a fixed pattern, the cost does not have any effect on smartphone users. There are two case scenarios for a smartphone game player: first, the cost incurred by him or her is acceptable, (that is, enjoyment balances the cost pressure) or the cost becomes unacceptable. Second, the users are not acceptable and the cost a sign of addiction. Under this case scenario, the user tends to become extreme for continuing to play smartphone games.

The flow experience has a direct effect on the satisfaction and the continued usage behaviour. Those who play smartphone games are mostly pleasure seekers. When playing a smartphone game, they feel relaxed, entertained, or concentrated; they may ease their pressure, or become detached from the real life; This increases their satisfaction degree which strengthens the continued usage behaviour. This viewpoint is consistent with a study conducted by Salehan and Negahban [16] on social application of mobiles. Users may become addicted if they excessively play smartphone games. Users may also play games on a mobile to escape from the real life.

As is decided by the special properties of smartphone, the perceived system quality has effects on the flow experience, the perceived peer influences, the satisfaction, and the continued usage behaviour. The connectivity and portability inherent of smartphone are main reasons that users choose it for a game terminal. Network speed and stability of the system may also affect satisfaction of the users. Therefore, when developing mobile terminals, mobile device providers should attach great importance to development of infrastructure to expand the scope for application of their mobile terminals.

The perceived peer influences have effects on the satisfaction and the continued usage behaviour. Users who play smartphone games are generally young people. They have certain requirements of participating the youth group. They are easy to accept new things and be influenced by other people. They are more willing to share interesting things and interact with other people. The increasingly developed SNS social gaming is an epitome for these. The perceived peer influences have great effects on the satisfaction and the continued usage behaviour. Frequent social contact is also one of major reasons for addiction to social gaming.

The study shows the satisfaction has the biggest effect on the continued usage behaviour, which is consistent with previous studies [36]. Developers of mobile games should attach great importance to the satisfaction of users to guarantee the continued usage behaviour.

\section{Conclusions}

Theoretically, based on the Expectation Confirmation Model as well as our previous studies on users' inherent behavioural motives, we study users' continued usage of smartphone for game playing. It proves that if users rely too much on smartphone, the factors such as the expectation confirmation, the perceived usefulness, etc. do not heavily affect the users' practical usage of smartphone. Although being restrained by smartphone, the model we established for the study shows that the mental impressions (such as the satisfaction, the flow experience, etc.), the technical limitations (imposed by perceived system quality), as well as the social influences (e.g. perceived peer influences) have effects on users' practical usage of smartphone, with the satisfaction having the biggest 
effect. By adding some related factors, we contribute to the construction of factors which are needed for establishing a model for continued usage behaviour.

In practical application, the study may provide some advices for the smartphone device providers and the game providers, and guide the usage behaviours of users.

Firstly, from the perspective of the mobile device providers, the study highlights that smartphone is different from ordinary mobile phones, due to it provides more powerful functions to run the game. This increases the possibility of continued usage behaviour of mobile games. The smart device providers should attach more importance to the quality of application of smartphone (system quality) as well as the diffusion (the perceived peer influences). While providing more devices with powerful functions, the mobile device providers should consider the entertainment and the quality of the mobile games.

Secondly, from the perspective of the game developers, when developing smartphone games, they should pay more attention to the users' satisfaction which determined by the flow experience, the perceived system quality, and the perceived peer influences. They should also notice the concentration of users in playing smartphone games. And they should also provide the higher quality gaming images and the more smooth operation, as well as satisfy users' desire to share their experiences. Under these circumstances, even if a smartphone game is well hard and the costs too high, the loyal player doesn't care these.

Lastly, the Salehan's study in 2013 shows that the continued usage of smartphone leads to the addiction [16]. The users we investigated are mostly young men and women, they are especially addicted to the smartphone games. The government and related organizations should come to know seriousness of the situation and take measures, such as establishing a classifying system for mobile games or an anti-addiction system, etc. For the smartphone users, they should be more temperate in playing smartphone games.

\section{Limitations}

Limitations of the study: Firstly, as smartphone-related research and development are in the infancy stage and very immature in China, and also the mobile gaming market in China is uneven. It is essential for China to synchronize the development of smartphone research and smartphone. Secondly, when studying the usage of smartphone games, this paper does not mention any specific game. Because different games have different requirements for users in terms of their behaviours, in later studies we should more deeply study specific behaviours of users when they play different smartphone games. Lastly, this study is a cross-section research. Because users' behaviours are always changing, we may, if doing a longitudinal study, offer more detailed explanations about users' behaviour.

\section{Acknowledgment}

Firstly, we really appreciate editor and anonymous reviewer helpful comments and valuable suggestions. Secondly, we are also grateful to the experts who revised the questionnaire and the persons who filled out the questionnaire.

\section{References}

[1] H. J. Park and S.-H. Kim, "A Bayesian network approach to examining key success factors of mobile games", Journal of Business Research, vol. 66, no. 9, (2013), pp. 1353-1359.

[2] J. Sung and Y. Yun, "Toward a More Robust Usability concept with Perceived Enjoyment in the context of mobile multimedia service", International Journal of Human Computer Interaction, vol. 1, no. 2, (2010), pp. 12.

[3] T.-M. Lin, S.-C. Chen and PP.-J. Kuo, "Motivations for Game-Playing on Mobile Devices-Using Smartphone as an Example", in Edutainment Technologies. Educational Games and Virtual Reality/Augmented Reality Applications, Springer, (2011), pp. 101-105.

[4] T. Zhou, "Understanding the effect of flow on user adoption of mobile games", Personal and ubiquitous computing, vol. 17, no. 4, (2013), pp. 741-748. 
[5] E. Park, "Determinants of player acceptance of mobile social network games: An application of extended technology acceptance model", Telematics and Informatics, vol. 31, no. 1, (2014), pp. 3-15.

[6] Bhattacherjee, "Understanding information systems continuance: an expectation-confirmation model", MIS quarterly, vol. 25, no. 3, (2001), pp. 351-370.

[7] M. Limayem, S.G. Hirt and C.M. Cheung, "How habit limits the predictive power of intention: the case of information systems continuance", Mis Quarterly, (2007), pp. 705-737.

[8] Bhattacherjee, J. Perols and C. Sanford, "Information Technology Continuance: A Theoretic Extension and Empirical Test", Journal of Computer Information Systems, vol. 49, no. 1, (2008).

[9] S. Hong, J.Y. Thong and K.Y. Tam, "Understanding continued information technology usage behavior: a comparison of three models in the context of mobile internet", Decision Support Systems, vol. 42, no. 3, (2006), pp. 1819-1834.

[10] X. Wu, 'A conceptual model of m-commerce customers' continuance intention based on the customers' perceived value", International Journal of Mobile Learning and Organisation, vol. 3, no. 3, (2009), pp. 243-257.

[11] T. Wang, "An empirical study of the impact of trial experiences on the continued usage of mobile newspapers", (2010).

[12] T.-PP. Liang and Y.-H. Yeh, "Effect of use contexts on the continuous use of mobile services: the case of mobile games", Personal and Ubiquitous Computing, vol. 15, no. 2, (2011), pp. 187-196.

[13] B. Kim, "The diffusion of mobile data services and applications: Exploring the role of habit and its antecedents", Telecommunications Policy, vol. 36, no. 1, (2012), pp. 69-81.

[14] Z. Deng, "Understanding customer satisfaction and loyalty: An empirical study of mobile instant messages in China", International Journal of Information Management, vol. 30, no. 4, (2010), pp. 289-300.

[15] C.-L. Hsu and H.-PP. Lu, "Why do people play on-line games? An extended TAM with social influences and flow experience", Information \& Management, vol. 41, no. 7, (2004), pp. 853-868.

[16] , M. Salehanand and A. Negahban, "Social networking on smartphones: When mobile phones become addictive", Computers in Human Behavior, vol. 29, no. 6, (2013), pp. 2632-2639.

[17] E. Hargittai, W.R. Neuman and O. Curry, "Taming the information tide: Perceptions of information overload in the American home", The Information Society, vol. 28, no. 3, (2012), pp. 161-173.

[18] W.H. DeLone and E.R. McLean, "Information systems success: the quest for the dependent variable", Information systems research, (1992), vol. 3, no. 1, pp. 60-95.

[19] , J.-C. Gu, S.-C. Lee and Y.-H. Suh, "Determinants of behavioral intention to mobile banking", Expert Systems with Applications, vol. 36, no. 9, (2009), pp. 11605-11616.

[20] J. Mulligan and B. Patrovsky, "Developing online games: An insider's guide", New Riders, (2003).

[21] H. Chun, H. Lee and D. Kim, "The integrated model of smartphone adoption: Hedonic and utilitarian value perceptions of smartphones among Korean college students", Cyberpsychology, Behavior, and Social Networking, vol. 15, no. 9, (2012), pp. 473-479.

[22] H. Sujan, B.A. Weitz and N. Kumar, "Learning orientation, working smart, and effective selling", The Journal of Marketing, (1994), pp. 39-52.

[23] R.P.P. Bagozzi and Y. Yi, "On the evaluation of structural equation models", Journal of the academy of marketing science, vol. 16, no. 1, (1988), pp. 74-94.

[24] H. Baumgartner and C. Homburg, "Applications of structural equation modeling in marketing and consumer research: a review", International Journal of Research in Marketing, vol. 13, no. 2, (1996), pp. $139-161$

[25] F. Joseph, J. Hair, "Multivariate data analysis (4th ed.): with readings", Prentice-Hall, Inc. 745, (1995).

[26] J.-B.E. Steenkamp and H. Van Trijp, "The use of LISREL in validating marketing constructs", International Journal of Research in marketing, vol. 8, no. 4, (1991), pp. 283-299.

[27] , J.C. Nunnally, I.H. Bernstein and J.M.t. Berge, "Psychometric theory", McGraw-Hill New York, vol. 226, (1967).

[28] Ha, Y. Yoon and M. Choi, "Determinants of adoption of mobile games under mobile broadband wireless access environment", Information \& Management, vol. 44, no. 3, (2007), pp. 276-286.

[29] J.-H. Wu and S.-C. Wang, "What drives mobile commerce?: An empirical evaluation of the revised technology acceptance model", Information \& management, vol. 42, no. 5, (2005), pp. 719-729.

[30] , S. Taylorand and PP.A. Todd, "Understanding information technology usage: A test of competing models", Information systems research, vol. 6, no. 2, (1995), pp. 144-176.

[31] F.D. Davis, "Perceived usefulness, perceived ease of use and user acceptance of information technology", MIS quarterly, (1989), pp. 319-340.

[32] D. Gefen, D.W. Straub and M.-C. Boudreau, And Regression: Guidelines For Research Practice, (2000).

[33] K.G. Burke, S.E. Kovar and PP.J. Prenshaw, "Understanding the satisfaction process for new assurance services: the of attitudes, expectations, disconfirmation and performance", Advances in Accounting role, vol. 20, (2003), pp. 43-75.

[34] M.R. Lepper and R.W. Chabay, "Intrinsic motivation and instruction: Conflicting views on the role of motivational processes in computer-based education", Educational Psychologist, vol. 20, no.4, (1985), pp. 217-230. 
International Journal of $u-$ and e- Service, Science and Technology

Vol. 10, No.5 (2017)

[35] R., Bartle, "Hearts, clubs, diamonds, spades: Players who suit MUDs", Journal of MUD research, vol. 1, no. 1 , (1996), pp. 19.

[36] T. Zhou, "Understanding continuance usage of mobile sites", Industrial Management \& Data Systems, vol. 113, no. 9, (2013), pp. 1286-1299.

\section{Author}

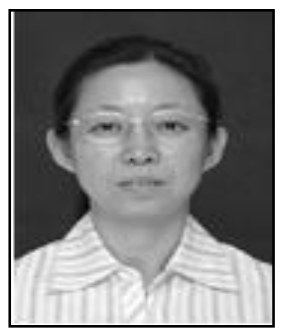

Xiaoning Wang, she is an Associate Professor at the School of Economic and Management, Xi'an Shiyou University, Shaanxi. Her current research interests include electronic commerce, mobile commerce and network economy. 